\title{
Uma crise tecnocientífica: reflexões filosóficas sobre a pandemia
}

\author{
A technoscientific crisis: philosophical reflections on the pandemic
}

\author{
Gilmar Evandro Szczepanik
}

\begin{abstract}
Resumo: O texto expressa uma investigação filosófica sobre a pandemia provocada pelo coronavírus. Primeiramente, realizamos a caracterização e a contextualização da crise tecnocientífica. Em seguida, verificamos que muitos dos problemas teóricos enfrentados pelos pesquisadores que lidam com questões associadas à pandemia já foram identificados e abordados como problemas teóricos ou metodológicos por diferentes filósofos da ciência, demonstrando que a filosofia pode auxiliar na compreensão sobre a atividade científica. Depois disso, o texto apresenta uma reflexão sobre a pandemia a partir da filosofia da tecnologia, demonstrando as valiosas contribuições que essa área pode oferecer aplicações úteis socialmente. Em síntese, trata-se de um ensaio filosófico em defesa da ciência e da tecnologia no contexto da pandemia Covid-19.

Palavras-chave: Ciência; Tecnologia; Tecnociência; Pandemia; Filosofia
\end{abstract}

Abstract: The work expresses a philosophical investigation into the pandemic caused by the coronavirus. First, we characterize and contextualize the technoscientific crisis. Then, we find that many of the theoretical problems faced by researchers dealing with issues associated with the pandemic have already identified and addressed as theoretical or methodological problems by different philosophers of science, demonstrating that philosophy can help in understanding scientific activity. After that, the text presents a reflection on the pandemic from the philosophy of technology, demonstrating the valuable contributions that this area can offer socially useful applications. In summary, this is a philosophical essay in defense of science and technology in the context of the Covid-19 pandemic.

Keywords: Science; Technology; Technoscience; Pandemic; Philosophy

\section{Introdução}

O objetivo do texto é identificar alguns dos principais problemas ocasionados pela pandemia do coronavírus e demonstrar como a filosofia da ciência e a filosofia da tecnologia podem ajudar a fornecer boas orientações em busca de respostas adequadas. Não estamos afirmando que os cientistas, tecnólogos e pesquisadores devem ser tutelados pelos filósofos dessas áreas, seguindo fielmente seus escritos e suas orientações. Contudo, consideramos que a tradição filosófica tem condições de fornecer valiosas contribuições teóricas às investigações relacionadas ao problema do Covid-19, possibilitando, inclusive, a recolocação de questões vinculadas à pandemia que podem mudar o rumo das

\footnotetext{
* Professor adjunto do departamento de Filosofia da Universidade Estadual do Centro-Oeste do Paraná, Guarapuava, PR. E-mail: gilmarevandro@unicentro.br ORCID: https://orcid.org/0000-0002-5236-1209
} 
investigações e reestruturar os procedimentos adotados até o momento. A cada problema levantado, especularemos quais seriam as possíveis orientações e quais medidas e atitudes seriam tomadas pelos teóricos da ciência e da tecnologia. Assim, transitaremos por diferentes autores a procura de respostas, buscando demonstrar que os pressupostos teórico/metodológicos apresentados pela filosofia da ciência e da tecnologia podem legitimar e fundamentar a adoção de medidas estipuladas por órgãos e autoridades competentes, justificando assim as posições adotadas, por exemplo, pela Organização Mundial da Saúde (OMS). Para atingirmos nosso objetivo, primeiramente faremos uma breve caracterização e contextualização do problema enfrentado a partir da declaração da pandemia pela OMS. Em seguida, apresentaremos os problemas enfrentados pelos pesquisadores e as alternativas existentes na filosofia.

Começamos pela contextualização. A pandemia do coronavírus é um problema grave e de proporções gigantescas que é responsável por um conjunto de crises. Falamos em um conjunto de crises porque podemos mencionar ao menos seis de naturezas distintas, embora estejam interligadas. Assim, tem-se i) uma crise econômica que afetou a indústria, o comércio, os trabalhadores e impactou o modo de produção e de consumo mundial; ii) uma crise política que atormentou os líderes e governantes de várias nações, fomentando tensões entre nações e instituições. A tensão política ficou explícita, por exemplo, nos discursos proferidos por autoridades que insinuaram que o vírus teria sido criado intencionalmente pelos chineses e nas manifestações contraditórias sustentadas por presidentes, governadores e prefeitos em torno do isolamento e do distanciamento social; iii) uma crise sanitária que obrigou a triplicar os cuidados com a higiene e a limpeza, pois estamos diante de um inimigo invisível a olho nu; iv) uma crise social que evidenciou ainda mais as desigualdades e as necessidades que afetam as pessoas das diversas classes sociais; v) uma crise ética e moral vivenciada principalmente pelos profissionais da saúde que, dada as limitações de insumos e equipamentos, precisam escolher quem será atendido e quem permanecerá desassistido. Adiciona-se a isso os riscos de contaminação e morte advindos do exercício de suas profissões. Por fim, a pandemia provocou também vi) uma crise tecnocientífica ${ }^{1}$, pois os cientistas e tecnólogos estão diante de um enorme problema que, até o momento, está resistindo a praticamente todas as investidas da ciência e da tecnologia. Nosso foco é tratar apenas dessa última crise. Sabemos que a filosofia tem também valiosas contribuições sobre as demais, mas, por uma questão metodológica, trataremos somente da crise tecnocientífica.

\footnotetext{
${ }^{1}$ Uma abordagem mais pormenorizada sobre a tecnociência pode ser encontrada em Echeverría, La revolución tecnocientífica.
} 


\section{A crise sob o pano de fundo da filosofia da ciência}

O primeiro problema enfrentado pelos cientistas e pesquisadores que se debruçam sobre a pandemia é a falta de um consenso sobre a forma adequada de solucionar o problema causado pelo Covid-19. No atual momento, ainda não há drogas ou procedimentos capazes de promover a cura. Há avanços significativos e muito promissores de diversas vacinas, mas que ainda carecem de comprovação de sua eficácia. No entanto, entre os especialistas no assunto, parece consensual que se faz necessário seguir as orientações preventivas de distanciamento social. As divergências explícitas entre os estudiosos da área produzem um grande desconforto no público leigo, fazendo com que ele passe a suspeitar e a duvidar da credibilidade, da capacidade e da autoridade da ciência.

Contudo, ao recorrermos a Thomas Kuhn (1970), observamos que as crises fazem parte da atividade científica e os profissionais afetados por elas fazem de tudo para solucioná-la. Elas são assim caracterizadas porque rompem o consenso paradigmático da ciência normal e instalam um período de incertezas e de instabilidades que pode ser rapidamente ajustado ou prolongado por um longo período de tempo. A extensão temporal da crise depende tão somente da habilidade dos cientistas em encaixar as peças do quebracabeça, diz Kuhn. Podemos compreender melhor a pandemia enfrentada hoje ao adotarmos uma perspectiva kuhniana, pois, segundo essa abordagem, embora os cientistas estejam lidando com um vírus novo, encontra-se consolidado entre os pesquisadores da área que o Covid-19 pertence à família do coronavírus ${ }^{2}$, cujos primeiros registros ocorreram em 1937, mas que foi somente devidamente isolado e batizado em 1965. Ele recebeu esse nome devido a suas características microscópicas que remetem a uma coroa. Nesse sentido, embora o Covid-19 tenha provocado transtornos mundiais, pode-se dizer que ele tem baixo potencial para gerar uma revolução científica, pois a comunidade científica já conseguiu, por exemplo, identificar e explicar o que é o Covid-19. Ela, inclusive, realizou o sequenciamento genético que possibilita entender a origem do vírus; sua evolução e suas possíveis mutações; e, as formas de transmissão e de contágio. Aos poucos, temos a impressão de que os cientistas estão conseguindo encaixar as peças do quebra-cabeça teórico no paradigma existente de um modo bastante exitoso.

Isso nos leva a pensar que a crise em curso não diz respeito à natureza do vírus. $\mathrm{O}$ dissenso que ainda perdura encontra-se na esfera pragmática, pois a comunidade científica ainda não sabe exatamente qual é o procedimento que deve ser adotado para curar as

\footnotetext{
${ }^{2}$ A comunidade científica identificou uma pluralidade de coronavírus que tem a capacidade de afetar tanto humanos quanto animais. Ao infectar os seres humanos, tais vírus provocam uma pluralidade de sintomas respiratórios indo desde um resfriado comum até infecções gravíssimas. Os tipos mais conhecidos de coronavírus até o momento são: i) Alpha coranvírus 229E e NL63; ii) Beta coronavírus OC43 e HKU1; iii) SARS-CoV e o iv) MERS-CoV.
} 
pessoas infectadas. Tampouco há um medicamento eficaz e devidamente comprovado cientificamente capaz de curar a doença ou de promover a imunização preventiva das pessoas ainda não contaminadas. Assim, a essa altura, suspeitamos dizer que essa não seja propriamente uma crise científica, mas uma crise tecnológica, como veremos mais abaixo.

O segundo problema que pode ser identificado nas investigações científicas sobre a pandemia é o problema das afirmações e generalizações precipitadas proferidas, algumas vezes, por pesquisadores que lidam diretamente com a pandemia. Tais profissionais, movidos pela euforia de uma possível conquista revolucionária ou pelo desejo de fama e de reconhecimento entre os pares, anunciam descobertas que, pouco tempo depois, acabam sendo refutadas e contraindicadas pela própria OMS. Sabemos que grande parte das pesquisas realizadas nos laboratórios por biólogos, infectologistas, biomédicos, geneticistas e demais profissionais partem do método indutivo, isto é, a partir de observações de casos particulares tentam fazer predições futuras. As limitações metodológicas da indução foram apontadas inicialmente por David Hume já no século XVIII. Como sabemos, a crítica ao método indutivo surge do fato de que observações particulares não nos permitem fazer inferências universais. Conforme Hume já alertava, do fato de termos visto o Sol nascer todos os dias no passado não temos nenhuma garantia de que ele nascerá amanhã. De modo análogo, o fato de que alguns pacientes reagiram bem a algumas drogas experimentais não nos permite inferir que essas drogas possam ser inadvertidamente administradas para todos os demais pacientes. A descoberta da cura para um paciente não implica necessariamente a descoberta da cura para todos os afetados. A generalização não é permitida justamente porque não temos legitimidade lógica e experimental para isso. Entretanto, a ciência reconhece a grandeza da cura de um indivíduo e considera isso um fato extraordinário, embora não represente o fim das investigações.

O terceiro problema que afeta os pesquisadores da pandemia está relacionado ao papel que eles atribuem aos testes científicos. Karl Popper considera, por exemplo, que a testabilidade é um importante critério para demarcar a ciência da não-ciência. Ao contrário do que muitas pessoas possam imaginar, os testes, segundo a concepção popperiana, não possuem a capacidade de confirmar se determinada teoria é verdadeira ou se determinada droga é extremamente eficiente no combate do novo coronavírus. Os testes têm um papel primordial em refutar hipóteses que foram desenvolvidas com o propósito de responder ao problema em questão, mas não têm a capacidade de garantir ou de estabelecer uma verdade absoluta. Ao direcionarmos nosso olhar para os procedimentos científicos voltados à pandemia, observamos pesquisadores adotando uma pluralidade de estratégias que envolvem uma investigação cuidadosamente das drogas existentes para ver se alguma delas tem potencial ou eficácia para combater o novo vírus. Destaca-se que essa 
não é uma investigação aleatória, mas fundamentada em protocolos e em evidências obtidas no controle de outras doenças. Assim, os testes possuem maior capacidade de demonstrar as limitações da teoria do que fornecer evidências a seu favor. Experimentos laboratoriais, por exemplo, já demonstraram a ineficácia de inúmeras drogas para o tratamento do Covid-19 como é o caso da cloroquina e da hidroxicloroquina. Nesse caso, os testes são categóricos e nos dão certeza de que tais drogas não devem ser ministradas aos pacientes com coronavírus, pois elas foram desenvolvidas para tratar de outras enfermidades. Desse modo, uso off label de tais medicamentos não é recomendado, pois não possui indicações homologadas pela comunidade de especialistas. Porém, outras drogas demonstraram recentemente alguma propensão na recuperação dos pacientes como é o caso do brequinar (que está em fase de teste para a leucemia), e do acetato de abiraterona, utilizado para o câncer de próstata. Porém, em termos popperianos, essas drogas necessitam de novas investigações. Os testes precisam ser ampliados e intensificados. O fato de existir alguma evidência em prol de determinada droga não fornece a ela uma enorme vantagem epistêmica ou pragmática perante as demais. A prudência científica impede que sejam tomadas conclusões precipitadas, pois um dos pilares da ciência popperiana é uma constante aproximação de verdades científicas, pois a ciência é, por natureza, uma atividade aberta e crítica. Os testes, os experimentos e as investigações são praticamente intermináveis nas áreas científicas. Não sabemos o que é exatamente uma verdade científica, embora estejamos sempre em busca dela em uma constante aproximação, diz Popper. Nesse sentido, os pesquisadores que investigam uma possível cura para a pandemia, necessitam continuar investigando.

Outro problema que perpassa as atuais investigações científicas é a dicotomia entre fato e valor. A distinção entre fato e valor foi inicialmente elaborada durante a revolução científica da primeira metade do século XVII e tornou-se um dos elementos identitários da ciência moderna. Na filosofia da ciência contemporânea, vários autores têm investigado o papel que os valores exercem na atividade científica entre os quais se destacam Kuhn ${ }^{3}$, Laudan $^{4}$, e Lacey ${ }^{5}$. A dicotomia entre fato e valor visa estabelecer autonomia à ciência em relação aos valores sociais, morais, religiosos ou políticos. Nesse sentido, a autoridade e a legitimidade da ciência não são concedidas a partir de um ambiente externo, mas são constituídas a partir da adoção de um método racional capaz de produzir um conhecimento objetivo e universal.

Contudo, a distinção radical entre fato e valor logo começou a ser problematizada, pois percebeu-se que há um conjunto de valores que são inerentes à própria atividade

\footnotetext{
${ }^{3} \mathrm{KUHN}$, The structure of scientific revolutions

${ }^{4}$ LAUDAN, Science and Values

${ }^{5}$ LACEY, Valores e atividade cientifica
} 
científica. Os valores intrínsecos à atividade científica foram denominados de valores cognitivos ou de valores epistêmicos e funcionam como critérios que servem para guiar e legitimar a própria ciência. Os principais valores epistêmicos identificados na ciência são a autonomia, a imparcialidade e a neutralidade. Por outro lado, também há os valores sociais que incorporam crenças, costumes religiosos, ideologias políticas, interesses econômicos e princípios morais. Tais valores são identitários e peculiares de um povo. Por esse motivo, na maioria dos casos, não podem ser universalizados. Além disso, os valores sociais podem se manifestar em intensidades distintas entre seus defensores. No transcorrer da história, a relação entre essas duas classes de valores nem sempre foi tranquila e também não o é nos dias de hoje.

Atualmente, as investigações científicas (e, consequentemente, os valores epistêmicos que as fundamentam) que tratam da pandemia ocasionada pelo coronavírus estão sob ataque. O mais preocupante é que esses ataques não ocorrem no campo epistemológico no qual seria possível debater a viabilidade, a coerência, a consistência, o poder preditivo, a capacidade explicativa, a eficácia de uma tese ou de um determinado experimento. Se as críticas fossem dirigidas de forma correta ao campo cognitivo/intelectual a ciência seria enaltecida, pois esse é um dos pressupostos de uma ciência aberta e não dogmática. Entretanto, os ataques à ciência atual são predominantemente oriundos de vários agentes externos à comunidade científica ou pouco comprometidos com ela. São agentes que ignoram as regras do jogo científico. É como se alguém que desconhecesse completamente as regras do xadrez dissesse que o movimento do bispo não pode ocorrer em diagonal ou que a torre não pode se deslocar apenas em linha reta. Ao tentar explicar para esse alguém que as regras do xadrez permitem tal movimentação, ele acaba partindo para ataques pessoais e fazendo de tudo para desacreditar o experiente enxadrista.

Os vários ramos da ciência que se dedicam ao estudo do novo coronavírus não são apenas questionados, mas chegam a ser negados por uma pluralidade de agentes que envolvem i) alguns governantes que consideram exagerada e descabida as recomendações de distanciamento e de isolamento social sugeridas pela ciência como a forma mais eficiente de se evitar o contágio e a propagação do vírus; ii) por empresários, comerciantes e economistas que tendem a ironizar e desacreditar que o vírus tenha a capacidade de provocar um número significativo de mortes, mesmo esses tendo dados empíricos que demonstram o elevado número de mortes no mundo; iii) por alguns líderes religiosos que alegam que a cura para o coronavírus será uma dádiva divina, a qual ocorrerá por meio da participação das orações, cultos e rituais religiosos; iv) por alguns estudiosos e pesquisadores precipitados que não conduzem de modo adequado suas investigações, pois estão mais preocupados com a fama e o prestígio do que a validade e a adequação 
acadêmica e científica da mesma; e v) pelo senso comum que não consegue ver o vírus, por se tratar de uma entidade microscópica, e, por esse motivo, duvida que será atingido e, por fim, vi) por alguns negacionistas que tendem a desacreditar a ciência e seus resultados somente porque ela aponta evidências contrárias as suas opiniões e crenças. O que há de comum entre os opositores da ciência é que eles desconhecem e/ou ignoram propositalmente as orientações que têm o potencial de prevenir e inibir o contágio. Por desconhecerem a sistematicidade e a complexidade da atividade científica, tais opositores consideram inadvertidamente que a ciência não está apta para resolver o problema em questão.

Embora tenhamos condições de desqualificar epistemologicamente a natureza dos atuais ataques à ciência, alegando que os argumentos sustentados por eles são fracos e problemáticos, eles têm apresentado danos significativos não somente à prática científica, mas principalmente à saúde e ao bem-estar dos seres humanos, dada a crescente escalada no número de contágios e de mortes. Ao atacar ou ignorar as indicações e as recomendações da ciência, tais agentes não ferem apenas a ciência, mas ajudam na propagação e na proliferação das pseudociências que, por sua, carecem de evidências e de comprovações. A consequência dessa atitude é a disseminação de desinformações, de teorias da conspiração e de misticismos, todos eles nocivos à população.

Diante desse cenário, faz-se necessário enfatizar que a ciência, desde os primórdios da modernidade, é regida por um conjunto de valores que concede a ela autonomia e imparcialidade. Assim, é um dever da ciência se afastar do subjetivismo e do relativismo, pois suas teorias têm a pretensão de descrever com o máximo rigor como é o mundo. A ciência lida com fatos. A ciência é episteme, isto é, é conhecimento. É uma atividade metódica e rigorosa. O fato de não gostarmos de ficar doente não cria em nós um escudo protetor que afasta todos os males e todas as doenças. Não está ao nosso alcance escolher qual doença iremos adquirir ou qual doença nos afetará no futuro, embora esteja ao nosso alcance desenvolver hábitos e adotar atitudes que podem minimizar ou maximizar o contágio de uma ou outra doença.

Como já mencionamos, embora a ciência não forneça respostas absolutamente verdadeiras, ela, ainda assim, fornece as melhores respostas para o problema da pandemia. Devemos seguir as orientações científicas porque a autoridade da ciência vem de uma i) minuciosa e criteriosa investigação de fatos; ii) de testes e de experimentos que seguem uma rigorosa metodologia, isto é, eles não são feitos ao acaso; iii) de uma legitimidade que é constituída pela comunidade científica, isto é, por um conjunto de pessoas altamente capacitadas que possuem competência e responsabilidade em dizer se tal descoberta é adequada ou não. Entretanto, a maioria das pessoas esquece que a ciência não faz milagres e que as descobertas científicas, muitas vezes, não têm uma aplicabilidade imediata. 
Assim, ao que parece, a ciência sozinha não será capaz de solucionar essa pandemia e tampouco outras que poderão surgir no futuro. Isso ocorre porque a ciência necessita da ajuda da tecnologia e de toda uma infraestrutura tecnológica. É justamente por esse motivo que, na introdução, falamos que a pandemia havia ocasionado também uma crise tecnocientífica. Na próxima seção, abordaremos as contribuições oferecidas pela filosofia da tecnologia na compreensão da pandemia.

\section{O pano de fundo da filosofia da tecnologia}

A filosofia da tecnologia, embora seja um ramo relativamente recente, tem adquirido cada vez maior importância e prestígio na comunidade filosófica. Isso ocorre justamente porque a tecnologia parece levantar questões filosóficas inevitáveis àqueles que têm a pretensão de compreender o mundo que os acerca. Desse modo, acreditamos que podemos recorrer a ela também para aprofundar nossa análise sobre o momento pandêmico que estamos vivenciando.

Todos aqueles que conhecem um pouco da história da ciência tendem a concordar que os avanços obtidos por ela, na atualidade, especialmente para essa pandemia, são magníficos. Isso é comprovado através dos avanços e das descobertas produzidas até o momento. Entretanto, parece que ainda não estamos tão próximos de um medicamento ou de uma vacina adequada que possa curar os infectados e prevenir futuros contágios. Estamos diante de um grande problema, pois sabemos o que é o vírus, mas não sabemos ainda como combatê-lo. Temos o conhecimento teórico que descreve com grande rigor e clareza sua natureza, mas ainda carecemos de instrumentos e de dispositivos eficientes para eliminá-lo ou torna-lo menos mortal ou agressivo. Suspeita-se dizer que talvez a ciência já tenha feito sua parte. Quem está devendo agora é a tecnologia.

A afirmação contida no parágrafo anterior se justifica, pois, a grande maioria das descobertas científicas não são automaticamente convertidas em artefatos e dispositivos funcionais. O reconhecimento de uma nova espécie, a confirmação da existência das ondas gravitacionais e a descoberta do Bóson de Higgs representam um enorme avanço científico, mas que, de súbito, não trazem nenhuma inovação tecnológica. Isso representa apenas que o investimento em ciência não implica necessariamente em um desenvolvimento tecnológico. Precisamos investir e fomentar a pesquisa e o desenvolvimento tecnológico. Os principais problemas enfrentados nesse momento do combate à pandemia parecem ser problemas de natureza tecnológica. Dependemos, mais do que nunca, de laboratórios bem equipados que consigam dar conta de analisar o material que foi coletado na população. Há, por exemplo, um grande número de testes que ainda não foram verificados, porque alguns equipamentos estão quebrados e os resultados precisam ser finalizados manualmente. Muitos laboratórios, sejam eles públicos ou privados, enfrentam a escassez de insumos e de reagentes básicos. Há escassez até de matéria-prima para o desenvolvimento de Equipamentos de Proteção Individual (EPIs). 
Percebe-se, então, que a corrida que presenciamos hoje para produzir uma droga que seja capaz de curar o Covid-19 é uma corrida tecnocientífica, que envolve, além dos cientistas e pesquisadores, a indústria farmacêutica, grandes laboratórios, governos, exército, investidores, administradores. Todos esses profissionais precisam trabalhar conjuntamente em prol de um bem maior.

Um elemento a ser observado nessa pandemia é que a primeira tecnologia empregada no combate ao coronavírus, e até o momento a mais eficaz, é uma tecnologia social. Tal tecnologia não está sintetizada em um artefato ou em um dispositivo, mas apresenta-se como um procedimento, uma instrução social que orienta as pessoas a ficarem em casa, diminuindo, consequentemente, a circulação e a aglomeração de pessoas, evitando, por conseguinte, a propagação de casos e o aumento do número de mortes. Tal tecnologia afetou diretamente milhões de vidas humanas em todo mundo e promoveu a mudança e a alteração da forma de vida das pessoas. Trata-se de uma medida técnica radical e praticamente inédita na história.

Entretanto, como a natureza ${ }^{6}$ dos problemas tecnológicos geralmente comporta uma pluralidade de ações e de respostas - não havendo, portanto, uma resposta certa, mas respostas mais adequadas ou mais eficientes - o problema da pandemia também comporta diferentes investidas com ações que envolvem, por exemplo, a criação, o desenvolvimento e a manutenção de respiradores mecânicos que são máquinas fundamentais que possibilitam a manutenção e o prolongamento da vida, haja vista que um dos principais sintomas dos infectados pelo coronavírus é uma grave crise respiratória. Além dos respiradores, também foram montados inúmeros leitos, hospitais de campanha, centros de triagem e de coleta de materiais para atender aos pacientes que procuram assistência médico-hospitalar. É admirável de ver a rapidez e a eficácia da engenharia nessas construções. Além disso, inúmeros profissionais estão empenhados em desenvolver novos testes - que sejam mais eficientes do que aqueles já existentes, que possam ser produzidos pela indústria nacional, e que sejam mais baratos - com intuito de fornecer um diagnóstico preciso ou conseguir identificar o vírus ainda em um estágio inicial. Além disso, estão sendo desenvolvidos inúmeros artefatos de proteção, os chamados EPIs (equipamentos de proteção individual) que envolvem máscaras médicas, luvas, macacão de segurança, aventais impermeáveis, entre outros. Soma-se a tudo isso, uma grande investida em desenvolver uma droga eficaz para essa doença. Em suma, o que a pandemia demonstrou é que a infraestrutura tecnológica desenvolvida para as áreas da saúde está aquém das necessidades.

Observamos que há múltiplas iniciativas sendo implementadas. Todavia, o cenário que observamos hoje ainda não é dos mais animadores. Isso ocorre porque, erroneamente, parece que o problema da pandemia será solucionado apenas pelos profissionais da saúde.

\footnotetext{
${ }^{6}$ Sobre a natureza dos problemas tecnológicos ver Rachel Laudan (Science and Values), Walter Vincenti (What engineers know and how they know it), Mario Bunge (Ser, saber, hacer), Ramón Queraltó (Ética, tecnología y valores en la sociedad global) e Nigel Cross (Engineering design methods: strategies for product design).
} 
Sabemos que os problemas tecnológicos demandam esforços conjuntos, pressupõem um trabalho inter/trans/pluri/multidisciplinar, mas o que temos observado é um esforço quase que unilateral que parte do Ministério da Saúde. O principal equívoco do momento é justamente a falta de protagonismo no combate ao Covid-19 do "Ministério da Ciência, Tecnologia, Inovações e Comunicações (MCTIC)" e do "Ministério da Educação” que são dois grandes centros que possuem uma enorme capacidade inventiva e criativa. A crise produzida pela pandemia necessita de esforços conjuntos dessas áreas. Sem esse trabalho coletivo, infelizmente, os resultados devem demorar mais para aparecerem.

Outro ponto importante para a filosofia da tecnologia que a pandemia produziu é a corrida da indústria farmacêutica para a criação de uma droga eficaz para combater a nova doença. Adaptando o argumento de Vermaas et. $\mathrm{al}^{7}$ ao contexto pandêmico, pode-se dizer que a primeira decisão que os engenheiros e pesquisadores precisam tomar é se o design será normal ou radical, pois isso traz consequências importantes. Se eles optarem pelo design normal (ou seja, um produto com ligeira variação que justifique a inovação), seguirão o caminho que já vem sendo percorrido por uma longa tradição. A configuração do artefato, assim como suas partes mais importantes, já se encontra determinada e o trabalho tem tudo para transcorrer dentro de uma normalidade. Neste caso, pode-se considerar que a inovação é um processo histórico no qual há uma adaptação e uma “evolução” gradual. Caso a opção seja feita pelo design radical (fortemente inovador) o desafio se multiplica, pois se faz necessário estabelecer os pressupostos básicos que permitirão o desenvolvimento do artefato tecnológico. Pelo que pode ser observado, os investigadores da indústria farmacêutica e dos laboratórios associados a ela têm buscado uma resposta pelas vias do design normal, pois estão examinando a eficácia das drogas já existentes que poderiam ser ministradas para combater o coronavírus. Uma das principais hipóteses inicialmente levantadas é que a cloroquina e a hidroxicloroquina poderiam vir a ser usadas no tratamento de pacientes graves, mas essa hipótese praticamente já está descartada. Entretanto, embora muitas drogas tenham um comportamento promissor em laboratório cujas variáveis são controláveis, na prática, elas podem não funcionar adequadamente, tornando-se até nocivas para os pacientes. Cabe ressaltar que isso não é uma exclusividade das áreas da saúde, pois o mesmo ocorre com muitos projetos tecnológicos das mais diversas áreas que, quando idealizados e apresentados no projeto ou na maquete, parecem dotados de perfeição, mas quando produzidos em tamanho e no contexto real revelam problemas que não foram previstos enquanto miniaturas.

\section{Considerações finais}

Esperamos ter demonstrado que a filosofia da ciência e a filosofia da tecnologia podem fornecer valiosas contribuições aos estudos sobre o coronavírus. Cabe ressaltar que todas as investidas científicas de se tentar combater a pandemia são válidas. A partir da

\footnotetext{
${ }^{7}$ VERMAAS, et al, A philosophy of technology, p. 28
} 
filosofia da ciência, pode-se dizer que todas as hipóteses científicas precisam ser levadas em consideração. Necessitamos instituir programas de pesquisa que possam desenvolver criteriosas investigações. Também é inegável que precisamos ser criativos e buscarmos respostas adequadas ao problema que nos cerca.

Entretanto, a resposta para a atual pandemia virá, necessariamente, da ciência e da tecnologia, pois elas detêm as melhores estratégias para solucionar os problemas teóricos e os problemas pragmáticos. Porém, quando tudo voltar à normalidade, precisamos recordar que os investimentos em ciência e tecnologia precisam ser considerados essenciais. Somente assim, estaremos mais capacitados e habilitados para enfrentarmos outros colapsos ou pandemias que surgirem no futuro.

\section{Referências}

BUNGE, Mario. Ser, saber, hacer. México: Paidós, 2002.

CROSS, Nigel. Engineering design methods: strategies for product design. England. 4a ed. John Wiley \& Sons Ltd, 2005.

ECHEVERRÍA, Javier. La revolución tecnocientífica. Madrid: Fondo de Cultura Económica de España, 2003

HUME, David. Investigações sobre o entendimento humano e sobre os princípios da moral. São Paulo: UNESP, 2004.

KUHN, Thomas. The structure of scientific revolutions. 2ed. Chicago: Foundations of the Unity of, 1970.

LACEY, Hugh. Valores e atividade científica. São Paulo (SP): Discurso, 1998.

LAUDAN, Larry. Science and Values. Berkeley: University of California Press, 1984.

LAUDAN, Rachel. (Ed.) The nature of technological knowledge. Are models of scientific change relevant? Dordrecht: Reidel Publishing Company, 1984.

POPPER, Karl. The logic of scientific discovery. London and New York: Hutchinson \&Co, 1959.

QUERALTÓ. Ramón. Ética, tecnología y valores en la sociedad global: el caballo de troya al revés. Madrid: Editorial Tecnos, 2003.

VERMAAS, Pieter et al. A philosophy of technology. from technical artefacts to sociotechnical systems. Morgan \& Claypool, Eindhoven University of technology, 2011.

VINCENTI, Walter. What engineers know and how they know it. Analytical Studies from Aeronautical History. London: The John Hopkins University Press, 1990. 